\title{
Vocal communication in wild chimpanzees: a call rate study
}

\author{
Anne-Sophie Crunchant ${ }^{1}$, Fiona A. Stewart ${ }^{2}$, Alex Piel ${ }^{\text {Corresp. } 2}$ \\ ${ }^{1}$ School of Biological and Environmental Sciences, Liverpool John Moores University, Liverpool, United Kingdom \\ 2 Department of Anthropology, University College London, London, United Kingdom \\ Corresponding Author: Alex Piel \\ Email address: a.piel@ucl.ac.uk
}

1. Background. Patterns of vocal communication have implications for species conservation: a change in calling behaviour can, for instance, reflect a disturbed habitat. More importantly, call rate is a parameter that allows conservation planners to convert call density into animal density, when detecting calls with a passive acoustic monitoring system (PAM). 2. Methods. We investigated chimpanzee (Pan troglodytes schweinfurthii) call rate during the late dry season in the Issa Valley, western Tanzania by conducting focal follows. We examined the socio-ecological factors that influence call production rate of savanna woodland chimpanzees.3. Results. We found that sex, proportion of time spent in a vegetation type, proportion of time spent travelling, time of the day, party size and swollen parous female presence had a significant effect on the call rate. Call rate differed among the different demographic classes with subadult and adult males vocalising twice as often as the subadult and adult females and three times as often as the juveniles.4. Applications: The use of PAM and recent statistical developments to estimate animal density is promising but relies on our knowing individual call rate, often not available for many species. With the improvement in automatic call detection, we anticipate that PAM will increasingly be broadly applied to primates but also across taxa, for conservation. 
2 Vocal communication in wild chimpanzees: a call rate study

3

4

6

7

Anne-Sophie Crunchant ${ }^{1}$, Fiona A. Stewart ${ }^{1,2}$, Alex K. Piel ${ }^{2}$

${ }^{1}$ School of Biological and Environmental Sciences, Liverpool John Moores University, Liverpool, UK

${ }^{2}$ Department of Anthropology, University College London, London, UK

Corresponding Author:

Alex Piel ${ }^{1}$

14 Taviton St., Bloomsbury, London WC1H 0BW, UK

Email address: a.piel@ucl.ac.uk

\section{Abstract}

1. Background. Patterns of vocal communication have implications for species conservation: a change in calling behaviour can, for instance, reflect a disturbed habitat. More importantly, call rate is a parameter that allows conservation planners to convert call density into animal density, when detecting calls with a passive acoustic monitoring system (PAM).

2. Methods. We investigated chimpanzee (Pan troglodytes schweinfurthii) call rate during the late dry season in the Issa Valley, western Tanzania by conducting focal follows. We examined the socio-ecological factors that influence call production rate of savanna woodland chimpanzees.

3. Results. We found that sex, proportion of time spent in a vegetation type, proportion of time spent travelling, time of the day, party size and swollen parous female presence had a significant effect on the call rate. Call rate differed among the different demographic classes with subadult and adult males vocalising twice as often as the subadult and adult females and three times as often as the juveniles.

4. Applications: The use of PAM and recent statistical developments to estimate animal density is promising but relies on our knowing individual call rate, often not available for many species. With the improvement in automatic call detection, we anticipate that PAM will increasingly be broadly applied to primates but also across taxa, for conservation.

\section{Introduction}

Vocal communication is a means through which senders and receivers exchange information via the production of acoustic signals and is likely influenced by natural and sexual selection (Seyfarth \& Cheney, 2003). Vocal signals are widely diversified among taxa, produced by insects, fish, herpetofauna, birds, and mammals to communicate in various social and environmental contexts, from alerting conspecifics to predator presence (e.g. Schel et al. 2013; 
41 Vitousek et al. 2007), maintaining bonds (e.g. Fedurek et al. 2013; Wanker et al. 1998), and
42 marking territorial boundaries (e.g. Peek 1972) among others. Similar to food, mates, and

42

43

44

45

46

47

48

49

50

51

52

53

54

55

56

57

58

59

60

61

62

63

64

65

66

67

68

69

70

71

72

73

74

75

76

77

78

79

80 territory, acoustic space can also be a scarce resource for which animals compete. Callers must adjust spatial, temporal and frequency patterns in response to both abiotic and biotic factors, especially the sounds of sympatric fauna (Araya-Salas et al., 2017). Widely spaced individuals use long calls to maintain inter-individual contact, which allow them to coordinate movements, especially for socially fluid animals with high fission-fusion dynamics like elephants (Loxodonta africana) (e.g. Leighty et al. 2008), spotted hyena (Crocuta crocuta), (e.g. Theis et al. 2007), bottlenose dolphins (Tursiops truncatus) (Janik \& Slater, 1998), beluga whales (Delphinapterus leucas) (O’Corry-Crowe et al., 2020), spider monkeys (Ateles spp.) (e.g. Spehar and Di Fiore 2013), bonobos (Pan paniscus) (e.g. Hohmann and Fruth 1994) and chimpanzees (e.g. Fedurek et al. 2014).

Call rate, the number of calls emitted per unit time per individual, can advertise male quality (Pedroso et al., 2003) and rate changes with caller age and sex class, time of day, group size and composition, social context, and environment, among others (Pérez-Granados et al., 2019). For instance, frog vocalizations are highly sexually different, energetically costly, and are mostly produced by males (Emerson \& Boyd, 1999). Dawn and dusk chorusing are common for many species, exploiting low ambient and minimal wind noise levels (Ey \& Fischer, 2009). Guereza black and white colobus monkey (Colobus guereza) calls are highly contagious and spread from one group to another (Schel \& Zuberbühler, 2012). Furthermore, loud calls in baboons advertise male quality, with high-ranking males calling more often (Kitchen et al., 2003; Fischer et al., 2004). Therefore, loud calls serve multiple functions and spatiotemporally shift in predictable ways, which can be reflected in a variation of call rates.

Additionally, vocal communication has implications for species conservation. A change in calling behaviour can reflect a disturbed habitat. Anthropogenic pressure affects call parameters, such as call duration and call frequency, and also the number of calls produced. For instance, a recent study at Los Tuxtlas in Mexico showed that howler monkeys (Alouatta palliata mexicana) produced fewer calls when exposed to anthropogenic noise (Cañadas Santiago et al., 2020). There is also evidence that African elephants change the acoustic structure of their alarm calls when threatened by bees or humans (Soltis et al., 2014). LaZerte et al. (2017) demonstrated that male mountain chickadees (Poecile gambeli) adjust songs, calls, and chorus composition with increasing ambient and (experimental) anthropogenic noise. More importantly, call rate is a parameter that allows conservation planners to convert call density (the number of calls per unit time per unit space) into animal density (i.e. the number of callers per unit space). Acoustic spatial capture-recapture (aSCR) and distance sampling methods can be used to estimate animal density by detecting vocalisations with acoustic sensors (e.g. Marques et al., 2013; Stevenson et al., 2015) . This can be particularly useful for cryptic, elusive, wide ranging and not visually detectable species. Using this method, numerous studies have reported abundance and density for various species, such as ovenbirds - Seiurus aurocapilla (Dawson \& Efford, 2009; Efford, Dawson, \& Borchers, 2009), frogs - Arthroleptella lighfooti (Borchers et al., 2015; Stevenson et

Peer] reviewing PDF | (2020:10:53491:2:0:NEW 2 Sep 2021) 
81 al., 2015), northern yellow-cheeked gibbons - Nomascus annamensis (Kidney et al., 2016). We

82

83

84

85

86

87

88

89

90

91

92

93

94

95

96

97

98

99

100

101

102

103

104

105

106

107

108

109

110

111

112

113

114

115

116

117

118

119

120

can convert caller density to population density once we know the call rate (Stevenson et al., 2015). Data on these parameters can be obtained by following individuals and recording call events. Obtaining these values is what motivated the current study. To accurately reflect the call rate of calls that can be detected on acoustic sensors, sometimes deployed hundreds of meters away from the caller for subsequent analyses, we focused only on screams, barks and pant hoots.

Chimpanzees ( $P$. troglodytes) are a gregarious species and form small parties that change in size and composition throughout the day. They move through a relatively large territory - e.g. from 7 to $40 \mathrm{~km}^{2}$ for forest dwelling chimpanzees (Newton-Fisher, 2003; Després-Einspenner et al., 2017) and 72 to $90 \mathrm{~km}^{2}$ for savanna dwelling chimpanzees (Samson \& Hunt, 2012; Pruetz \& Herzog, 2017) and are often hundreds of metres apart. Thus, they must rely on vocal communication to reveal to others information about, for instance, fruiting trees, predator presence, and movement coordination within and between parties. Eckhardt et al. (2015) reported that male chimpanzees from Taï Forest (Ivory Coast) remained out of visual range of conspecifics for almost half of observation time but within auditory range $(<1 \mathrm{~km})$ for $70 \%$ of the time, suggesting chimpanzee vocalisations serve an important function as contact calls between spatially separated individuals. Some of the earliest studies on chimpanzee vocalisations noted an overall sex difference in pant hooting rates in adults, with males calling more than females (Marler \& Hobbett 1975; Goodall 1986), and in some cases, all-female parties calling so rarely to make inter-sex comparisons impossible (Clark 1996; Clark and Wrangham 1994). Only recently, however, were these observations supported with empirical data from a single community in Tai Forest (Kalan, 2019). Thus, despite a half-century of investigation into chimpanzee vocalisations, much is still not known about call rate, and especially how it changes between sexes, behavioural contexts, and communities. This intra- and inter-community rate variability has bearing on what value is used for density studies that rely on PAM data, where call rate is a critical parameter (Marques et al., 2013).

The aim of this study was twofold: first, we wanted to estimate the call rate of chimpanzees living in a savanna woodland habitat. Given the known sex differences in chimpanzee acoustic communication, e.g. call rate and acoustic parameters (Kalan, 2019), we calculated the call rate for the following age/sex classes: subadult and adult females, subadult and adult males and male and female juveniles. Second, we investigated socio-ecological factors influencing call rate. We therefore examined the effect of (1) party size: we expected chimpanzees to call more often as party size increased due to the chorus effect and contagious calling (Fedurek, Schel \& Slocombe, 2013); (2) presence of a swollen female: we expected that call rate would be higher when callers were in parties with at least one parous swollen female (Fedurek, Donnellan \& Slocombe, 2014); (3) time of day: we expected a temporal pattern with chimpanzees calling more often in the morning and late afternoon (e.g. Piel 2018); (4) vegetation: chimpanzees seem to spread more when in open area, likely because of higher visibility and we consequently expected chimpanzees to call more often when present in the open vegetation (woodland); (5) activity: two important call functions are to indicate fruiting trees and

Peer) reviewing PDF | (2020:10:53491:2:0:NEW 2 Sep 2021) 
121

122

123

124

125

126

127

128

129

130

131

132

133

134

135

136

137

138

139

140

141

142

143

144

145

146

147

148

149

150

151

152

153

154

155

156

157

158

159

160

maintain spatial cohesion, especially during travelling, hence we expected that the proportion of time spent travelling or feeding would be positively correlated to the call rate (Clark \& Wrangham, 1993; Fedurek, Donnellan \& Slocombe, 2014).

\section{Materials \& Methods}

\section{Study site}

We collected data for three months during the late dry season, between August and October 2019, in the Issa Valley, western Tanzania (Fig.1). The study area of about $70 \mathrm{~km}^{2}$ is comprised of a series of valleys separated by steep mountains and flat plateaus, with an altitudinal gradient ranging from 1050 to $1650 \mathrm{~m}$ above sea level. Vegetation is dominated by miombo woodland and also includes grassland, swamp and riparian forest. For analyses, we collapsed vegetation categories into 'open' (woodland, grassland, swamp) and 'closed' (riparian forest), see Fig.1. The region is one of the driest and most open that is inhabited by chimpanzees (Moore 1992) and characterised by two seasons: wet (November to April) and dry (May to October). Annual rainfall averaged $1220 \mathrm{~mm}$ per annum (range from 930 to $1490 \mathrm{~mm}$ from 2009 to 2014) and temperatures ranged from $11^{\circ} \mathrm{C}$ to $38^{\circ} \mathrm{C}$ (Piel et al., 2017).

\section{Study subjects}

The study site covers the territory of at least two chimpanzee communities (one habituated community and one or more neighbouring communities). When the study began, the habituated Issa community comprised nine adult females, seven adult males, four subadult males, one subadult female, three juveniles and four infants (Table 1). During the study period, one female (AZ) was not yet fully habituated so we have not included data on her, as researcher presence likely influenced her natural behaviour (Crofoot et al., 2010; Nowak et al., 2014). Two individuals (adult female and infant) were killed and a female gave birth during the study period. The habituated community has a home range $\geq 55 \mathrm{~km} 2$.

\section{Data collection}

We selected a focal chimpanzee (adult, subadult or juvenile) each morning and tried to follow $\mathrm{him} /$ her for the entire day (i.e. from nest to nest). We conducted instantaneous focal animal sampling, with a scan defined as the behaviour of the animal recorded every five minutes, when we collected data on caller location (GPS), behaviour (travelling, feeding, resting, grooming, playing, other), vegetation (open or closed) and party size, defined as the number of juveniles, subadults and adults seen. We further noted all vocal behaviour ad libitum of the focal, including the type of vocalisation (pant grunt, grunt, hoot, pant hoot, bark, scream or combinations of different types - see e.g. Crockford 2019; Goodall 1986 for descriptions of chimpanzee vocalisations). Successive calls were considered as new events when separated by more than one second. We included only vocalisations that involved at least a scream, a pant-hoot or bark in the 
161

162

163

164

165

166

167

168

169

170

171

172

173

174

175

176

177

178

179

180

181

182

183

184

185

186

187

188

189

190

191

192

193

194

195

196

197

198

199

analyses, to match the calls that can be potentially recorded by an acoustic recorder deployed about 500m away from the caller. We thus excluded grunts and other closed calls that do not propagate far. We included only hours of follow data with at least 10 scans/hour, which corresponds to at least fifty minutes of observation per hour.

Data analyses

We conducted all analyses in R v.3.6.1 (R Core Team, 2019). For each hour of focal follow, we determined the proportion of time spent travelling, feeding and other behaviours, in open or closed vegetation by the focal individual. We defined the proportion of time in e.g. open vegetation as the number of scans in which the focal was observed in open vegetation divided by the total number of scans where the focal was in view.

To model the number of calls per hour (call rate, CR) as a function of the covariates, we used a negative binomial distribution GAM with a log link function, that allowed us to account for overdispersion. Fixed covariates were (1) time (T, categorical with 11 levels: from 7 am to $6 \mathrm{pm}),(2)$ mean hourly party size (PS, continuous), (3) presence of swelling female in the party (PrS, categorical with 2 levels: presence or absence), (4) proportion of time spent in closed vs. open vegetation (F, continuous), (5) proportion of time spent feeding (Fe, continuous), (6) proportion of time spent travelling ( $\mathrm{Tr}$, continuous) and (7) age-sex class (AS, categorical with 3 levels: adult-subadult female, adult-subadult male, juvenile). To incorporate the dependency among follows on the same day, we used 'individual' as a random intercept and to incorporate the dependency among observations of the same individual at the same time, we used "date" as a random intercept. We used the package mgcv (Wood, 2017) to fit the model. We centred and scaled continuous predictors.

We tested predictors for collinearity by calculating variation inflation factors (VIF) using the package car (Fox \& Weisberg, 2018) in an equivalent linear model including only the fixed effects from each model fitted with the package MASS (Brian et al., 2020). Multicollinearity was not present (maximum VIF: PS=1.53). We verified model assumptions by plotting residuals versus fitted values and QQ-plots. We ran a set of models and ranked them by AICc value.

\section{Results}

In total, we analysed 487 hours of follows on twenty-one chimpanzees $(21.2 \pm 12.2 \mathrm{hrs}$ per individual, Table 1). Call rate varied individually, ranging from an average of 0.24 to 3.41 calls per hour.

Factors influencing the call rate

We did model averaging among models with $\triangle \mathrm{AICc}<2$. The significant effects in the best averaged model are age/sex, proportion of time in the forest, proportion of time travelling, timeof-day, presence of swollen female, party size, and the two random intercept terms (individual and date) (Table 2). 
200 Results of the GAM revealed that the age-sex class had a significant effect on call rate: overall, 201 Issa chimpanzees exhibited a mean call rate of 1.91 with a $95 \%$ CI of [1.52-2.40]) calls per hour 202 for the subadult and adult males, 0.84 with a 95\% CI of [0.59-1.21] calls per hour for the 203 subadult and adult females, and 0.50 with a 95\% CI of [0.24-1.05] calls per hour for the 204 juveniles. With 95\% confidence, males call between 1.5 and 3.8 times as frequently as females 205 and between 1.3 and 7.9 times as frequently as juveniles. Chimpanzees vocalised significantly 206 more as the proportion of time spent in open vegetation and as the proportion of time spent 207 traveling increased (Table 3). The smooth effect of time reveals call rates being highest in the 208 morning decreasing thereafter, before increasing late afternoon (Fig. 2).

209

\section{Discussion}

211 In this study, we sought to establish the mean call rate of different demographic classes of wild 212 chimpanzees, as well as examine the socio-ecological factors that influence call production rate. 213 We found that time spent in a specific vegetation type, time spent travelling, time of the day, 214 party size and swollen parous female presence had significant effects on call rate.

215

1) Call rate among demographic classes

218 Our results confirm early reports on sex differences between adult chimpanzee loud call production (Clark 1996) and a recent study that subadult and adult male chimpanzees more than twice as often as subadult and adult females (Kalan, 2019). The sexual dimorphism seems to be

220

221

222

223

224

225

226

227

228

229

230

231

232

233

234

235

236

237

238

239 even more pronounced for forest than savanna woodland dwelling chimpanzees. At Taï, males produced on average $2.5 \pm 1.08$ calls per hour and females produced $0.88 \pm 0.32$ calls per hour (Kalan, 2019), compared to $1.91 \pm 0.12$ calls per hour for the males and $0.84 \pm 0.18$ calls per hour for the females at Issa (this study). We propose two explanations for this sex difference: (1) necessity of maintaining strong bonds and/or (2) sexual selection. Chimpanzees are malephilopatric, where males stay in their natal territory, while females disperse at sexual maturity and migrate to neighbouring communities (e.g. Moore et al. 2015; Nishida 1968). This sex difference in dispersal explains strong male-male relationships (e.g. Mitani 2009). Males tend to develop stronger bonds with other male community members with whom they spend more time, forming a linear dominance hierarchy and developing affiliations and coalitions. East African female chimpanzees, on the contrary, are far less gregarious than males, travel less, and spend most of their time alone or with their offspring in their core home range (Wrangham and Smuts 1980).

2) Ecological factors

We found that chimpanzees called most at two times of day (morning and evening) and from open (miombo woodland) compared to closed (riparian forest) vegetation. This temporal information is important for conservationists, who can for instance record sounds with PAM systems at these periods to maximise the likelihood of detecting calls and simultaneously limit the number of audio files to analyse. There are ecological and social reasons for these patterns. 
240 Temporally, the bimodal pattern that we found in this study is similar to what has been reported

241

242

243

244

245

246

247

248

249

250

251

252

253

254

255

256

257

258

259

260

261

262

263

264

265

266

267

268

269

270

271

272

273

274

275

276

277

278

279 previously at Issa (Piel 2018) and elsewhere (e.g. Wilson et al. 2007; Wrangham 1975).

Vocalisations allow parties to coordinate movements, notably prior to arrival at their nesting sites (Fischer \& Zinner, 2011) or feeding trees (Clark \& Wrangham, 1993). Ecologically, callers may exploit ideal sound transmission conditions. The Acoustic Adaptation Hypothesis predicts that animals may adjust their vocal signals to maximize signal transmission and minimize sound degradation, specifically within each environment in which calls occur (Waser \& Waser, 1977; Ey \& Fischer, 2009; Brown \& Waser, 2017). Environmental metrics, such as temperature gradients, humidity and wind, vary with time of day, and can degrade signals, resulting in structural changes to the primary sound (Waser \& Brown, 1984). Relatedly, the natural habitat distorts signals as distance from the sound origin increases. Open vegetation, with increased wind-induced noises compared to closed vegetation, can further degrade signals but sounds attenuate faster in closed vegetation because of tree density (Brown \& Waser, 2017). If chimpanzees rely more on close contact calls (not included in this study) to maintain party cohesion in closed, rather than open vegetation, the fact that chimpanzees vocalize significantly more often in open vegetation might be explained by their activity, rather than the external environment. Furthermore, the Issa landscape is dominated $(>65 \%)$ by miombo woodland vegetation, thus it is unsurprising that they vocalize more from open than closed vegetation types. Calls made in open vegetation could serve multiple purposes. First, individuals may spread out more in these areas, given that food sources are more widely distributed here than in closed areas and so calls are functioning to preserve party cohesion. Additional data on interindividual distance (e.g. party spread) in each vegetation type would help us resolve this. Second, calls travel further in open compared to closed vegetation, with fewer trees to attenuate sound (although see Waser \& Brown 2017), so individuals also may be calling to communicate with distantly located parties. Often counter calls are heard from these woodland pant hoots (AC, pers. obs.), but we do not have comparative data from forests.

3) Travelling and feeding activities

We evaluated the effect of activity, namely time spent travelling and feeding, on call production rate. While previous studies have shown that chimpanzees frequently pant-hoot at food sources (Clark and Wrangham 1993; Fedurek et al. 2014; Wrangham 1977), call rate did not change with the proportion of time spent feeding in our study. However, our brief field season took place during the late dry season, when fruit availability is highest (McLester et al., 2019). The abundance of food might reduce competition among individuals and thus depress the need for calling. Furthermore, we did not incorporate which food items were consumed. Fedurek and colleagues (2014) have shown that male chimpanzees were more likely to pant hoot at highquality food patches and thus we suggest that subsequent studies consider food type consumption during calling bouts.

The number of calls increased as the proportion of time spent travelling increased. It has long been demonstrated that loud calls facilitate fusion events and help regulate grouping

Peer) reviewing PDF | (2020:10:53491:2:0:NEW 2 Sep 2021) 
280

281

282

283

284

285

286

287

288

289

290

291

292

293

294

295

296

297

298

299

300

301

302

303

304

305

306

307

308

309

310

311

312

313

314

315

316

317

318

319

dynamics and coordination among community members during travel (e.g. Goodall 1986). In other communities, males travel significantly more after a pant hoot is produced (Mitani \& Nishida, 1993) and males are more likely to repeat a call prior to, rather than after, fusion with other males (Fedurek, Donnellan \& Slocombe, 2014).

4) Party size and presence of parous swollen female We have shown that call rate was positively related to party size. Coordinating movement with a higher number of individuals requires more communication, especially for decision making and coordinating party fusion (Fischer \& Zinner, 2011). Furthermore, a previous study has shown that the number of aggressive events is positively correlated to the number of males in a party (Muller 2002), and thus the number of calls produced during agonistic events (i.e. barks, screams and pant hoots) would likely increase with the number of males in the party.

Finally, the presence of a swollen female in the party did also impact call production rate, as expected. It has indeed been shown that males prefer to mate with parous females and are more involved in male-male competition in their presence because parous females are attractive to males, which exhibit aggressive displays and courtship behaviour during these times (Muller et al. 2006).

5) Implications and Limitations Variability in chimpanzee calling is well known, described in nearly every study on the topic; early work attributed variability to age, sex, context, party size, and community, among others (Goodall 1986; Arcadi and Wrangham 1993, 1994; Mitani et al. 1992, 1994). For the most part, these studies reported variability in the context of call function. In the current study, however, we were not interested in call function. Whilst similar to some previous work, we report on contextspecific variability, our primary interest is in the implications of call rate variability for conservation studies that rely on PAM to extract animal densities. For example, sex ratio, vegetation types and proportions, and activity budgets vary between communities. Our results here begin to reveal how call rate changes with each of these, which has direct bearing on how its parameterised in density analyses. Specifically, for communities that range across more open vegetation - Issa (Tanzania), Fongoli (Senegal), Semliki (Uganda) - call rate should reflect this in density models, varying with sensor location.

Those implications notwithstanding, we are cautious interpreting these results and conclusions should not be generalized to scenarios other than that where the data were collected. We sampled over a single and brief 3-month season and recorded only 487 hours of follows (compared to Kalan (2019) who recorded 731.5 hours of follows across 10 months). With food availability, party size and the number of swollen females highest at this time of year (Piel, unpublished data), it is likely that our data are inflated against annual means. More data collected across multiple seasons would resolve this uncertainty and would result in seasonal variation in call production, especially lower call rates in the early wet season when party size declines and fewer females exhibit maximum tumescence. We were also unable to equally balance data 
320

321

322

323

324

325

326

327

328

329

330

331

332

333

334

335

336

337

338

339

340

341

342

343

344

345

346

347

348

349

350

351

352

353

354

355

356

357

358

359

collection across the community, with some individuals being followed only $5 \mathrm{hrs}$ and some more than $30 \mathrm{hrs}$. This was mostly due to the difficulty of following recently habituated females. Given that the call rate variation between two individuals is likely to be greater than the variation within the same individual, rather than over-sample fewer individuals, we chose to sample more individuals.

6) Future directions

Future studies can not only build off these results by adding more data, but also additional predictor variables that may influence chimpanzee call rate. Specifically, further analyses would benefit from evaluating the effect of rank on call rate. For instance, rank has been implicated in influencing call rate in chacma baboons (Papio cynocephalus ursinus) (Kitchen et al., 2003), gelada monkeys (Theropithecus gelada) (Benitez et al., 2016), orang-utans (Pongo pygmaeus) (Mitani, 1985) and also non-primate [fallow bucks (Dama dama) (Pitcher et al., 2014)] species, and strongly suggests that vocal communication is influenced by sexual selection. In support of this, multiple studies examining chimpanzee rank and call production reveal a positive relationship between male quality, testosterone, and rank (Clark, 1993; Clark \& Wrangham, 1993; Mitani \& Nishida, 1993; Fedurek et al., 2016). There is not yet empirical evidence however, demonstrating female preference for male vocalisations.

Moreover, we recommend that subsequent studies include a spatial component. For example, chimpanzees spend the majority of their time in the core of their home range, usually representing about 75-90\% of their total territory (Wilson, Hauser \& Wrangham, 2007). When males conduct patrols in high risk areas, e.g. croplands or territorial boundaries, call rate declines significantly (Wilson, Hauser \& Wrangham, 2007). Chimpanzees from savanna habitats have far larger home ranges - e.g. $\geq 55 \mathrm{~km}^{2}$ at Issa (Giuliano, unpublished data) or about $90 \mathrm{~km}^{2}$ at Fongoli (Pruetz \& Herzog, 2017) - than forest dwelling chimpanzees - e.g. $7 \mathrm{~km}^{2}$ at Budongo (Newton-Fisher, 2003). Suzuki (1969) proposed that the low density and widely distributed foods in these savanna landscapes may promote more nomadism in savanna than in forest chimpanzees and Moore (1992) suggested that the sheer scale of these home ranges may make them indefensible. Forest-dwelling chimpanzees are well known to be highly xenophobic and respond aggressively to members from neighbouring communities (e.g. Goodall 1986; Mitani et al. 2010; Mitani and Watts 2005; Watts and Mitani 2001; Wilson and Wrangham 2003). In contrast to forest dwelling chimpanzees, recent observations at Issa suggest that chimpanzees there may be more tolerant of neighbouring individuals, sharing large parts of their territory with non-community members (pers. obs). Similarly, as mentioned in the introduction, many species modulate their call rate in response to human disturbance - e.g. amphibians (Sun \& Narins, 2005), birds (LaZerte, Otter \& Slabbekoorn, 2017), and elephants (Soltis et al., 2014). For example, in Bili, northern DRC, chimpanzees call significantly less when they nest near human settlements (Hicks \& Roessingh, 2010). The Issa study site lies not far from a human settlement and a road. Despite the fact that snare encounter rates increased with distance from the research station (Piel et al., 2015), the presence of cattle herding is still frequently observed in the area 
360 (AC, pers. obs.). We recommend that subsequent work evaluates whether Issa chimpanzees

361

362

363

364

365

366

367

368

369

370

371

372

373

374

375

376

377

378

379

380

381

382

383

384

385

386

387

388

389

390

391

392

393

394

395

396

397

adjust their call rate near areas of increased human presence (e.g. road or cattle herders).

\section{Conclusions}

Whilst we discussed the inherent importance of biological and social predictors of call rate in wild chimpanzees, this study was primarily motivated by the need to establish call rate to estimate chimpanzee density from passive acoustic monitoring (PAM) and acoustic spatial capture-recapture (aSCR) methods (Crunchant et al., unpublished data). Chimpanzee call rate is highly sexually dimorphic and like many other chimpanzee behaviours (e.g. Kühl et al. 2019; Whiten et al. 1999) shows community-specific patterns. To estimate an average and unbiased call rate, and consequently an unbiased density estimate, we need to weight values of each age/sex class by the proportion of each demographic class constituting the community. Similar to great ape nest decay and nest production rates, even context-specific call rate is likely to vary between communities. We recommend call rate studies to be conducted in parallel to PAM deployment. Call rates can only be studied in habituated chimpanzees, however, as follows are necessary to add context to vocalizing behaviour. Comparison of call rates between communities will be instrumental to evaluate how strongly it can affect density estimation from aSCR methods. The use of PAM and aSCR to estimate chimpanzee density is promising and with the improvement of automatic call detection, we anticipate that PAM will become more common in the primatologist's toolbox.

\section{Acknowledgements}

We thank the Tanzanian Wildlife Research Institute (TAWIRI), Commission for Science and Technology (COSTECH), and the Tanganyika District for permission to carry out research at Issa. We are also extremely grateful to all field assistants of the Greater Mahale Ecosystem Research and Conservation (GMERC) project and Caroline Fryns for their help in the field. Many thanks to Edward McLester for statistical advice and Ineke Knot, Ben Stevenson, Barbara Fruth, Tiago Marques and one anonymous reviewer for feedback on a previous version of the manuscript. The UCSD/Salk Center for Academic Research and Training (CARTA) generously provided long-term support for the Issa project.

\section{References}

Araya-Salas M, Wojczulanis-Jakubas K, Phillips EM, Mennill DJ, Wright TF. 2017. To overlap or not to overlap: context-dependent coordinated singing in lekking long-billed hermits. Animal Behaviour 124:57-64. DOI: 10.1016/j.anbehav.2016.12.003.

Benitez ME, le Roux A, Fischer J, Beehner JC, Bergman TJ. 2016. Acoustic and temporal variation in gelada (Theropithecus gelada) loud calls advertise male quality. International Journal of Primatology 37:568-585. DOI: 10.1007/s10764-016-9922-0. 
398 Borchers D, Stevenson B, Kidney D, Thomas L, Marques T. 2015. A unifying model for 399 capture-recapture and distance sampling surveys of wildlife populations. Journal of the 400 American Statistical Association 110:195-204. DOI: 10.1080/01621459.2014.893884.

401 Brian R, Venables B, Bates DM, Hornik K, Gebhardt A, Firth D. 2020. Package "MASS." 402 Brown CH, Waser PM. 2017. Primate habitat acoustics. In: Quam RM, Ramsier MA, Fay RR, 403 Popper AN eds. Primate hearing and communication. Cham: Springer,. DOI: 10.1007/978-3404 319-02904-7.

405 Cañadas Santiago S, Dias PAD, Garau S, Coyohua Fuentes A, Chavira Ramírez DR, Canales 406 Espinosa D, Rangel Negrín A. 2020. Behavioral and physiological stress responses to local 407 spatial disturbance and human activities by howler monkeys at Los Tuxtlas, Mexico. Animal 408 Conservation 23:297-306. DOI: 10.1111/acv.12541.

409 Clark AP. 1993. Rank differences in the production of vocalizations by wild chimpanzees as a 410 function of social context. American Journal of Primatology 31:159-179.

411 Clark AP. 1996. Phrase structure of wild chimpanzee pant hoots: Patterns of production and 412 interpopulation variability. American Journal of Primatology 39:159-178.

413 Clark AP, Wrangham RW. 1993. Acoustic analysis of wild chimpanzee pant hoots: Do Kibale 414 Forest chimpanzees have an acoustically distinct food arrival pant hoot? American Journal of 415 Primatology 31:99-109. DOI: 10.1002/ajp.1350310203.

416 Clark AP, Wrangham RW. 1994. Chimpanzee arrival pant hoots: Do they signify food or stats?? 417 International Journal of Primatology 15:185-205. DOI: 10.1007/BF02735273.

418 Crockford C. 2019. Why does the chimpanzee vocal repertoire remain poorly understood and 419 what can be done about it? In: Boesch C, Wittig R eds. The Chimpanzees of the Taï Forest. 420 Cambridge: Cambridge University Press, 394-409. DOI: 10.1017/9781108674218.025.

421 Crofoot MC, Lambert TD, Kays R, Wikelski MC. 2010. Does watching a monkey change its 422 behaviour? Quantifying observer effects in habituated wild primates using automated 423 radiotelemetry. Animal Behaviour 80:475-480. DOI: 10.1016/j.anbehav.2010.06.006.

424 Dawson DK, Efford MG. 2009. Bird population density estimated from acoustic signals. Journal 425 of Applied Ecology 46:1201-1209. DOI: 10.1111/j.1365-2664.2009.01731.x.

426 Després-Einspenner M-L, Howe EJ, Drapeau P, Kühl HS. 2017. An empirical evaluation of 427 camera trapping and spatially explicit capture-recapture models for estimating chimpanzee 428 density. American Journal of Primatology:1-12. DOI: 10.1002/ajp.22647.

429 Eckhardt N, Polansky L, Boesch C. 2015. Spatial Cohesion of Adult Male Chimpanzees (Pan 430 troglodytes verus) in Taï National Park, Côte D'Ivoire. American Journal of Primatology 431 77:125-134. DOI: 10.1002/ajp.22316.

432 Efford MG, Dawson DK, Borchers DL. 2009. Population density estimated from locations of 433 individuals on a passive detector array. Ecology 90:2676-2682.

434 Emerson SB, Boyd SK. 1999. Mating vocalizations of female frogs: Control and evolutionary 435 mechanisms. Brain, Behavior and Evolution 53:187-197. DOI: 10.1159/000006594.

436 Ey E, Fischer J. 2009. The "Acoustic Adaption Hypothesis" - A review of the evidence from 437 birds, anurans, and mammals. Bioacoustics 19:21-48. 
438 Fedurek P, Donnellan E, Slocombe KE. 2014. Social and ecological correlates of long-distance 439 pant hoot calls in male chimpanzees. Behavioral Ecology and Sociobiology 68:1345-1355. DOI: 440 10.1007/s00265-014-1745-4.

441 Fedurek P, Machanda ZP, Schel AM, Slocombe KE. 2013. Pant hoot chorusing and social bonds 442 in male chimpanzees. Animal Behaviour 86:189-196. DOI: 10.1016/j.anbehav.2013.05.010.

443 Fedurek P, Schel AM, Slocombe KE. 2013. The acoustic structure of chimpanzee pant-hooting 444 facilitates chorusing. Behavioral Ecology and Sociobiology 67:1781-1789. DOI:

$44510.1007 / \mathrm{S} 00265-0$.

446 Fedurek P, Slocombe KE, Enigk DK, Thompson ME, Wrangham RW, Muller MN. 2016. The

447 relationship between testosterone and long-distance calling in wild male chimpanzees.

448 Behavioral Ecology and Sociobiology 70:659-672. DOI: 10.1007/s00265-016-2087-1.

449 Fischer J, Kitchen DM, Seyfarth RM, Cheney DL. 2004. Baboon loud calls advertise male

450 quality: Acoustic features and their relation to rank, age, and exhaustion. Behavioral Ecology and 451 Sociobiology 56:140-148. DOI: 10.1007/s00265-003-0739-4.

452 Fischer J, Zinner D. 2011. Communication and cognition in primate group movement. 453 International Journal of Primatology 32:1279-1295. DOI: 10.1007/s10764-011-9542-7.

454 Fox J, Weisberg S. 2018. An $\{\mathrm{R}\}$ Companion to Applied Regression, Third Edition.

455 Goodall J. 1986. The chimpanzees of Gombe: Patterns of behavior. Cambridge, MA: Harvard 456 University Press.

457 Hartig F. 2020. DHARMa: Residual Diagnostics for Hierarchical (Multi-level / Mixed)

458 Regression models. R package version 0.3.1.

459 Hicks TC, Roessingh P. 2010. Chimpanzees (Pan troglodytes schweinfurthii) in the northern

460 democratic republic of Congo adapt their long-distance communication behavior to human

461 hunting pressure. Institute for Biodiversity and Ecosystem Dynamics (IBED).

462 Hohmann G, Fruth B. 1994. Structure and use of distance calls in wild bonobos (Pan paniscus).

463 International Journal of Primatology 15:767-782. DOI: 10.1007/BF02737430.

464 Janik VM, Slater PJB. 1998. Context-specific use suggests that bottlenose dolphin signature

465 whistles are cohesion calls. Animal behaviour 56:829-838.

466 Kalan AK. 2019. Evidence for sexual dimorphism in chimpanzee vocalizations: a comparison of 467 male and female call production and acoustic parameters. In: Boesch C, Wittig R eds. The 468 Chimpanzees of the Taï Forest. Cambridge, UK: Cambridge University Press, 410-421. DOI: $46910.1017 / 9781108674218.026$.

470 Kidney D, Rawson BM, Borchers DL, Stevenson BC, Marques TA, Thomas L. 2016. An 471 efficient acoustic density estimation method with human detectors applied to gibbons in 472 Cambodia. PLoS ONE 11:e0155066. DOI: 10.1371/journal.pone.0155066.

473 Kitchen DM, Seyfarth RM, Fischer J, Cheney DL. 2003. Loud calls as indicators of dominance 474 in male baboons (Papio cynocephalus ursinus). Behavioral Ecology and Sociobiology 53:374475 384. DOI: 10.1007/s00265-003-0588-1.

476 Kühl HS, Boesch C, Kulik L, Haas F, Arandjelovic M, Dieguez P, Bocksberger G, McElreath 477 MB, Agbor A, Angedakin S, Ayimisin EA, Bailey E, Barubiyo D, Bessone M, Brazzola G, 
478 Chancellor R, Cohen H, Coupland C, Danquah E, Deschner T, Diotoh O, Dowd D, Dunn A, 479 Egbe VE, Eshuis H, Fernandez R, Ginath Y, Goedmakers A, Granjon A-C, Head J, Hedwig D, 480 Hermans V, Imong I, Jeffery KJ, Jones S, Junker J, Kadam P, Kambere M, Kambi M, Kienast I, 481 Kujirakwinja D, Langergraber K, Lapuente J, Larson B, Lee K, Leinert V, Llana M, Maretti G, 482 Marrocoli S, Mbi TJ, Meier AC, Morgan B, Morgan D, Mulindahabi F, Murai M, Neil E, 483 Niyigaba P, Ormsby LJ, Pacheco L, Piel AK, Preece J, Regnaut S, Rundus A, Sanz C, van 484 Schijndel J, Sommer V, Stewart F, Tagg N, Vendras E, Vergnes V, Welsh A, Wessling EG, 485 Willie J, Wittig RM, Yurkiw K, Zuberbuehler K, Kalan AK. 2019. Human impact erodes 486 chimpanzee behavioral diversity. Science 4532:eaau4532. DOI: 10.1126/science.aau4532.

487 LaZerte SE, Otter KA, Slabbekoorn H. 2017. Mountain chickadees adjust songs, calls and chorus 488 composition with increasing ambient and experimental anthropogenic noise. Urban Ecosystems 489 20:989-1000. DOI: 10.1007/s11252-017-0652-7.

490 Lehmann J, Boesch C. 2008. Sexual differences in chimpanzee sociality. International Journal of 491 Primatology 29:65-81. DOI: 10.1007/s10764-007-9230-9.

492 Leighty KA, Soltis J, Wesolek CM, Savage A. 2008. Rumble vocalizations mediate interpartner 493 distance in African elephants, Loxodonta africana. Animal Behaviour 76:1601-1608. DOI:

494 10.1016/j.anbehav.2008.06.022.

495 Marler P, Hobbett L. 1975. Individuality in a long-range vocalization of wild chimpanzees.

496 Zeitschrift für Tierpsychologie 38:97-109. DOI: 10.1111/j.1439-0310.1975.tb01994.x.

497 Marques TA, Thomas L, Martin SW, Mellinger DK, Jarvis S, Morrissey RP, Ciminello C-A,

498 DiMarzio N. 2012. Spatially explicit capture-recapture methods to estimate minke whale density 499 from data collected at bottom-mounted hydrophones. Journal of Ornithology 152:445-455. DOI: 500 10.1007/s10336-010-0535-7.

501 Marques TA, Thomas L, Martin SW, Mellinger DK, Ward JA, Moretti DJ, Harris D, Tyack PL. 502 2013. Estimating animal population density using passive acoustics. Biological Reviews 88:287503 309. DOI: 10.1111/brv.12001.

504 McLester E, Brown M, Stewart FA, Piel AK. 2019. Food abundance and weather influence 505 habitat-specific ranging patterns in forest- and savanna mosaic-dwelling red-tailed monkeys 506 (Cercopithecus ascanius). American Journal of Physical Anthropology 170:217-231. DOI: 507 10.1002/ajpa.23920.

508 Mitani JC. 1985. Sexual selection and adult male orangutan long calls. Animal Behaviour 509 33:272-283. DOI: 10.1016/S0003-3472(85)80141-X.

510 Mitani JC. 2009. Male chimpanzees form enduring and equitable social bonds. Animal 511 Behaviour 77:633-640. DOI: 10.1016/j.anbehav.2008.11.021.

512 Mitani JC, Nishida T. 1993. Contexts and social correlates of long-distance calling by male 513 chimpanzees. Animal Behaviour 45:735-746. DOI: 10.1163/1568539X-00003259.

514 Mitani JC, Watts DP. 2005. Correlates of territorial boundary patrol behaviour in wild 515 chimpanzees. Animal Behaviour 70:1079-1086. DOI: 10.1016/j.anbehav.2005.02.012. 516 Mitani JC, Watts DP, Amsler SJ. 2010. Lethal intergroup aggression leads to territorial 517 expansion in wild chimpanzees. Current Biology 20:507-508. DOI: 10.1016/j.cub.2010.04.021. 
518 Moore J. 1992. Savanna chimpanzees. In: Nishida T, McGrew P, Marler P, Pickford M, de Waal 519 F eds. Topics in primatology, vol.1 Human origins. Tokyo, Japan: University of Tokyo Press, $520 \quad 99-118$.

521 Moore DL, Langergraber KE, Vigilant L. 2015. Genetic analyses suggest male philopatry and 522 territoriality in savanna-woodland chimpanzees (Pan troglodytes schweinfurthii) of Ugalla, 523 Tanzania. International Journal of Primatology 36:377-397. DOI: 10.1007/s10764-015-9830-8.

524 Muller MN. 2002. Agonistic relations among Kanyawara chimpanzees. In: Boesch C, Hohmann

525 G, Marchant LF eds. Behavioural diversity in chimpanzees and bonobos. Cambridge, UK:

526 Cambridge University Press, 112-23.

527 Muller MN, Thompson ME, Wrangham RW. 2006. Male chimpanzees prefer mating with old

528 females. Current Biology 16:2234-2238. DOI: 10.1016/j.cub.2006.09.042.

529 Muller MN, Wrangham RW. 2004. Dominance, aggression and testosterone in wild 530 chimpanzees: A test of the "challenge hypothesis." Animal Behaviour 67:113-123. DOI: 531 10.1016/j.anbehav.2003.03.013.

532 Newton-Fisher NE. 2003. The home range of the Sonso community of chimpanzees from the

533 Budongo Forest, Uganda. African Journal of Ecology 41:150-156. DOI: 10.1046/j.1365-

534 2028.2003.00408.x.

535 Nishida T. 1968. The social group of wild chimpanzees in the Mahali Mountains. Primates 536 9:167-224. DOI: 10.1007/BF01730971.

537 Nowak K, Le Roux A, Richards SA, Scheijen CPJ, Hill RA. 2014. Human observers impact

538 habituated samango monkeys' perceived landscape of fear. Behavioral Ecology 25:1199-1204.

539 DOI: 10.1093/beheco/aru110.

540 O'Corry-Crowe G, Suydam R, Quakenbush L, Smith TG, Lydersen C, Kovacs KM, Orr J,

541 Harwood L, Litovka D, Ferrer T. 2020. Group structure and kinship in beluga whale societies.

542 Scientific Reports 10:1-21. DOI: 10.1038/s41598-020-67314-w.

543

544 Pedroso SS, Barber I, Svensson O, Fonseca PJ, Amorim MSC. 2013. Courtship Sounds

545 Advertise Species Identity and Male Quality in Sympatric Pomatoschistus spp. Gobies. PLoS

546 ONE 8(6): e64620. doi:10.1371/journal.pone.0064620.

547 Peek FW. 1972. An experimental study of the territorial function of vocal and visual display in

548 the male red-winged blackbird (Agelaius phoeniceus). Animal Behaviour 20:112-118. DOI:

549 10.1016/S0003-3472(72)80180-5.

550 Pérez-Granados C, Bota G, Giralt D, Barrero A, Gómez-Catasús J, Bustillo-De La Rosa D, Traba

551 J. 2019. Vocal activity rate index: a useful method to infer terrestrial bird abundance with

552 acoustic monitoring. Ibis 161:901-907. DOI: 10.1111/ibi.12728.

553 Piel AK. 2018. Temporal patterns of chimpanzee loud calls in the Issa Valley, Tanzania:

554 Evidence of nocturnal acoustic behavior in wild chimpanzees. American Journal of Physical

555 Anthropology 166:530-540. DOI: 10.1002/ajpa.23609. 
556 Piel AK, Lenoel A, Johnson C, Stewart FA. 2015. Deterring poaching in western Tanzania: The 557 presence of wildlife researchers. Global Ecology and Conservation 3:188-199. DOI:

558 10.1016/j.gecco.2014.11.014.

559 Pitcher BJ, Briefer EF, Vannoni E, McElligott AG. 2014. Fallow bucks attend to vocal cues of

560 motivation and fatigue. Behavioral Ecology 25:392-401. DOI: 10.1093/beheco/art131.

561 Pruetz JD, Herzog NM. 2017. Savanna chimpanzees at Fongoli, Senegal, navigate a fire

562 landscape. Current Anthropology 58:S337-S350. DOI: 10.1086/692112.

563 R Core Team. 2019. R: A language and environment for statistical computing. R Foundation for 564 Statistical Computing.

565 Samson DR, Hunt KD. 2012. A thermodynamic comparison of arboreal and terrestrial sleeping 566 sites for dry-habitat chimpanzees (Pan troglodytes schweinfurthii) at the Toro-Semliki Wildlife

567 Reserve, Uganda. American Journal of Primatology 74:811-818. DOI: 10.1002/ajp.22031.

568 Schel AM, Townsend SW, Machanda Z, Zuberbühler K, Slocombe KE. 2013. Chimpanzee

569 alarm call production meets key criteria for intentionality. PLoS ONE 8:e76674. DOI:

570 10.1371/journal.pone.0076674.

571 Schel AM, Zuberbühler K. 2012. Dawn chorusing in guereza colobus monkeys. Behavioral

572 Ecology and Sociobiology 66:361-373. DOI: 10.1007/s00265-011-1282-3.

573 Seyfarth RM, Cheney DL. 2003. Signalers and Receivers in Animal Communication. Annual

574 Review of Psychology 54:145-173. DOI: 10.1146/annurev.psych.54.101601.145121.

575 Soltis J, King LE, Douglas-Hamilton I, Vollrath F, Savage A. 2014. African elephant alarm calls

576 distinguish between threats from humans and bees. PLoS ONE 9:e89403. DOI:

577 10.1371/journal.pone.0089403.

578 Spehar SN, Di Fiore A. 2013. Loud calls as a mechanism of social coordination in a fission-

579 fusion taxon, the white-bellied spider monkey (Ateles belzebuth). Behavioral Ecology and

580 Sociobiology 67:947-961. DOI: 10.1007/s00265-013-1520-y.

581 Stevenson BC, Borchers DL, Altwegg R, Swift RJ, Gillespie DM, Measey GJ. 2015. A general

582 framework for animal density estimation from acoustic detections across a fixed microphone

583 array. Methods in Ecology and Evolution 6:38-48. DOI: 10.1111/2041-210X.12291.

584 Sun JWC, Narins PM. 2005. Anthropogenic sounds differentially affect amphibian call rate.

585 Biological Conservation 121:419-427. DOI: 10.1016/j.biocon.2004.05.017.

586 Suzuki A. 1969. An ecological study of chimpanzees in a savanna woodland. Primates 10:103587 148. DOI: 10.1007/BF01730979.

588 Theis KR, Greene KM, Benson-Amram SR, Holekamp KE. 2007. Sources of variation in the

589 long-distance vocalizations of spotted hyenas. Behaviour 144:557-584. DOI:

$59010.1163 / 156853907780713046$.

591 Vitousek MN, Adelman JS, Gregory NC, St Clair JJH. 2007. Heterospecific alarm call

592 recognition in a non-vocal reptile. Biology Letters 3:632-634. DOI: 10.1098/rsbl.2007.0443.

593 Wanker R, Apcin J, Jennerjahn B, Waibel B. 1998. Discrimination of different social

594 companions in spectacled parrotlets (Forpus conspicillatus): Evidence for individual vocal

595 recognition. Behavioral Ecology and Sociobiology 43:197-202. DOI: 10.1007/s002650050481. 
596 Waser PM, Brown CH. 1984. Is there a " sound window " for primate communication.

597 Behavioral Ecology and Sociobiology 15:73-76.

598 Waser PM, Waser MS. 1977. Experimental studies of primate cocalization: specializations for 599 long-distance propagation. Zeitschrift für Tierpsychologie 43:239-263. DOI: 10.1111/j.1439600 0310.1977.tb00073.x.

601 Watts DP, Mitani JC. 2001. Boundary patrols and intergroup encounters in wild chimpanzees. 602 Behaviour 138:299-327.

603 Whiten A, Goodall J, McGrew WC, Nishida T, Reynolds V, Sugiyama Y, Tutin CEG, 604 Wrangham RW, Boesch C. 1999. Cultures in chimpanzees. Nature 399:15-18.

605 Wilson ML, Hauser MD, Wrangham RW. 2007. Chimpanzees (Pan troglodytes) modify 606 grouping and vocal behaviour in response to location-specific risk. Behaviour 144:1621-1653. 607 Wilson ML, Wrangham RW. 2003. Intergroup Relations in Chimpanzees. Annual Review of 608 Anthropology 32:363-392. DOI: 10.1146/annurev.anthro.32.061002.120046.

609 Wood, S.N. (2017) Generalized Additive Models: An Introduction with R

610 (2nd edition). Chapman and Hall/CRC.

611 Wrangham R. 1975. The behavioural ecology of chimpanzees in Gombe National Park, 612 Tanzania.

613 Wrangham RW. 1977. Feeding behaviour of chimpanzees in Gombe National Park, Tanzania. 614 In: Clutton-Brock TH ed. Primate ecology: studies of feeding and ranging behavior in lemurs, 615 monkey and apes. London, UK: Academic Press, 503-538. DOI: 10.1016/b978-0-12-176850616 8.50022-6.

617 Wrangham RW, Smuts BB. 1980. Sex differences in the behavioural ecology of chimpanzees in 618 the Gombe National Park, Tanzania. Journal of reproduction and fertility. Supplement:13-31. 619 
Figure 1

Study site in Issa Valley, Western Tanzania and chimpanzee locations during the late dry season from focal follows (7239 5 -min scans).

Each dot represents the location of an individual and a heatmap shows the preferentially used areas during the study period.
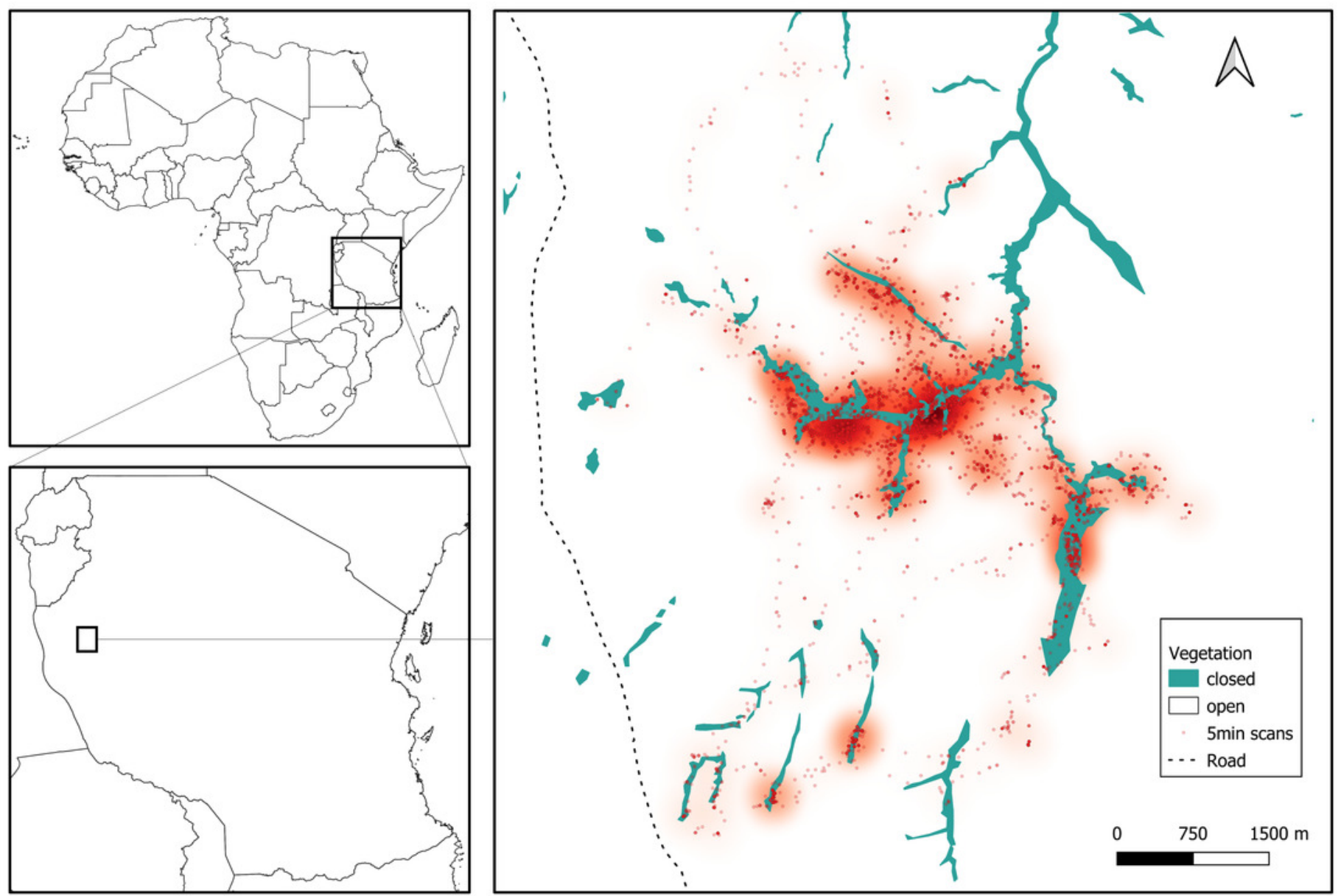
Figure 2

Call rate changes over the course of the day. Rates were highest in the morning and decreased thereafter, before increasing in the late afternoon

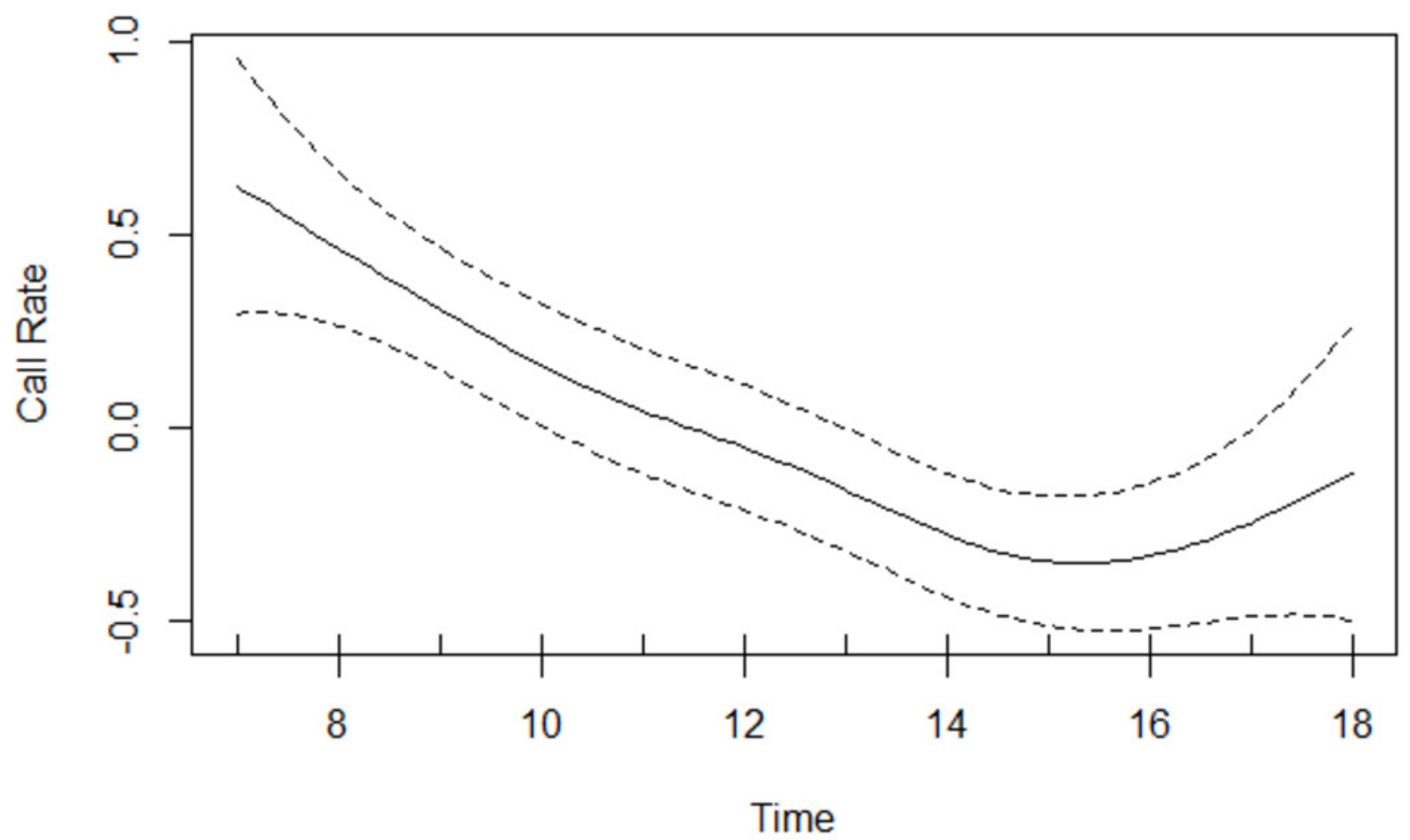




\section{Table $\mathbf{1}$ (on next page)}

Summary of the number of focal follow hours per individual and their call rate. Mean call rate, defined as the number of pant-hoots, screams or barks per hour is presented with the individual range in brackets. 
1 Table 1. Summary of the number of focal follow hours per individual and their call rate. Mean call rate, 2 defined as the number of pant-hoots, screams or barks per hour is presented with the individual range in 3 brackets.

4

\begin{tabular}{|c|c|c|c|c|}
\hline Name & Age & Sex & \# hrs of follow & Call rate (\# calls/hr, min-max) \\
\hline$A Z$ & Adult & Female & 0 & NA \\
\hline BS & Adult & Female & 13 & $0.38[0-2]$ \\
\hline $\mathrm{JU}$ & Adult & Female & 11 & $1.73[0-4]$ \\
\hline $\mathrm{KL}$ & Adult & Female & 5 & $0.60[0-2]$ \\
\hline KN & Adult & Female & 9 & $2.22[0-5]$ \\
\hline $\mathrm{KJ}$ & Adult & Female & 14 & $1.14[0-3]$ \\
\hline MA & Adult & Female & 18 & $1.56[0-5]$ \\
\hline ZA & Adult & Female & 17 & $0.24[0-2]$ \\
\hline KS & Sub-adult & Female & 26 & $0.31[0-3]$ \\
\hline BG & Adult & Male & 41 & $3.41[0-11]$ \\
\hline EL & Adult & Male & 23 & $2.04[0-8]$ \\
\hline IM & Adult & Male & 35 & $2.37[0-9]$ \\
\hline KT & Adult & Male & 37 & $2.65[0-14]$ \\
\hline MY & Adult & Male & 33 & $1.06[0-6]$ \\
\hline SM & Adult & Male & 35 & $2.23[0-9]$ \\
\hline WA & Adult & Male & 23 & $1.48[0-8]$ \\
\hline $\mathrm{DH}$ & Sub-adult & Male & 25 & $2.60[0-7]$ \\
\hline MS & Sub-adult & Male & 29 & $1.45[0-6]$ \\
\hline SN & Sub-adult & Male & 30 & $2.90[0-13]$ \\
\hline WG & Sub-adult & Male & 30 & $1.53[0-8]$ \\
\hline MW & Juvenile & Female & 5 & $1.20[0-2]$ \\
\hline KK & Juvenile & Male & 28 & $0.57[0-5]$ \\
\hline BN & Juvenile & Male & 0 & $\mathrm{NA}$ \\
\hline
\end{tabular}




\section{Table 2 (on next page)}

Model selection. CR: call rate; AS: age/sex class; PrS: presence swelling female; Fe: proportion of time spent feeding; F: proportion of time spent in closed vegetation; $\mathrm{Tr}$ : proportion of time spent travelling; PS: party size; T: time, F: follow, D: date. 
1 Table 2. Model selection. CR: call rate; AS: age/sex class; PrS: presence swelling female; Fe: 2 proportion of time spent feeding; F: proportion of time spent in closed vegetation; Tr: proportion 3 of time spent travelling; PS: party size; T: time, F: follow, D: date. 4

\begin{tabular}{l|lllll} 
Model & df & logLiK & AlCC & delta & weight \\
\hline$C R \sim A S+P r S+F+T r+P S+T+F$ & 24 & -814.710 & 1681.5 & 0.00 & 0.094 \\
$C R \sim A S+P r S+F+T r+P S+T+F+D$ & 24 & -814.710 & 1681.5 & 0.00 & 0.094 \\
$C R \sim A S+P r S+F+T r+T+F$ & 25 & -814.471 & 1682.4 & 0.84 & 0.062 \\
$C R \sim A S+P r S+F+T r+T+F+D$ & 25 & -814.471 & 1682.4 & 0.84 & 0.062 \\
$C R \sim A S+P r S+F e+F+T r+P S+T+F$ & 25 & -814.078 & 1682.6 & 1.09 & 0.055 \\
$C R \sim A S+P r S+F e+F+T r+P S+T+F+D$ & 25 & -814.078 & 1682.6 & 1.09 & 0.055 \\
$C R \sim A S+F+T r+T+F$ & 24 & -816.013 & 1683.0 & 1.50 & 0.045 \\
$C R \sim A S+F+T r+T+F+D$ & 24 & -816.013 & 1683.0 & 1.50 & 0.045 \\
$C R \sim \operatorname{Pr} S+F+T r+T+F$ & 26 & -813.445 & 1683.4 & 1.88 & 0.037 \\
$C R \sim \operatorname{Pr}+F+T r+T+F+D$ & 26 & -813.445 & 1683.4 & 1.88 & 0.037 \\
$C R \sim \operatorname{Pr} S+F e+F+T r+T+F$ & 26 & -812.771 & 1684.1 & 2.54 & 0.027 \\
$C R \sim \operatorname{Pr}+F e+F+T r+T+F+D$ & 27 & -812.771 & 1684.1 & 2.54 & 0.027
\end{tabular}




\section{Table 3(on next page)}

Outcome of a GAM investigating the effect of time, age/sex class, presence of swollen parous female, party size (PS), proportion of time spent in the closed area and proportion of time spent travelling on chimpanzee call rate for the averaged best models. 
1 Table 3. Outcome of a GAM investigating the effect of time, age/sex class, presence of swollen 2 parous female, party size (PS), proportion of time spent in the closed area and proportion of time 3 spent travelling on chimpanzee call rate for the averaged best models.

4

\begin{tabular}{lllll}
\hline Predictors & \multicolumn{4}{c}{ Parameter Estimate } \\
\cline { 2 - 5 } & Estimate & Std. E. & z value & $\operatorname{Pr}(>|\mathrm{z}|)$ \\
\hline Intercept & 0.477 & 0.225 & 2.115 & $3.44 \mathrm{e}-02^{*}$ \\
\hline Age/sex class (male) & & & & \\
$\begin{array}{l}\text { Subadult/adult female } \\
\text { juvenile }\end{array}$ & -0.864 & 0.252 & 3.413 & $\begin{array}{l}6.43 \mathrm{e}-04^{* * *} \\
4.79 \mathrm{e}-03^{* *}\end{array}$ \\
\hline Closed area (forest) & -1.129 & 0.456 & 2.820 & $6.977 \mathrm{e}-03^{* *}$ \\
\hline $\begin{array}{l}\text { Swollen parous female } \\
\text { presence }\end{array}$ & -0.171 & 0.063 & 2.698 & $2.536 \mathrm{e}-01^{*}$ \\
\hline Party size & 0.315 & 0.141 & 2.236 & $2.619 \mathrm{e}-02^{* *}$ \\
\hline Travel & 0.164 & 0.734 & 2.223 & $1.60 \mathrm{e}-04^{* * *}$
\end{tabular}

5 Parameter estimates are reported for all terms in the averaged best three models.

$6 \quad *=p<0.05 ; * *=p<0.01 ; * * *=p<0.001$. 